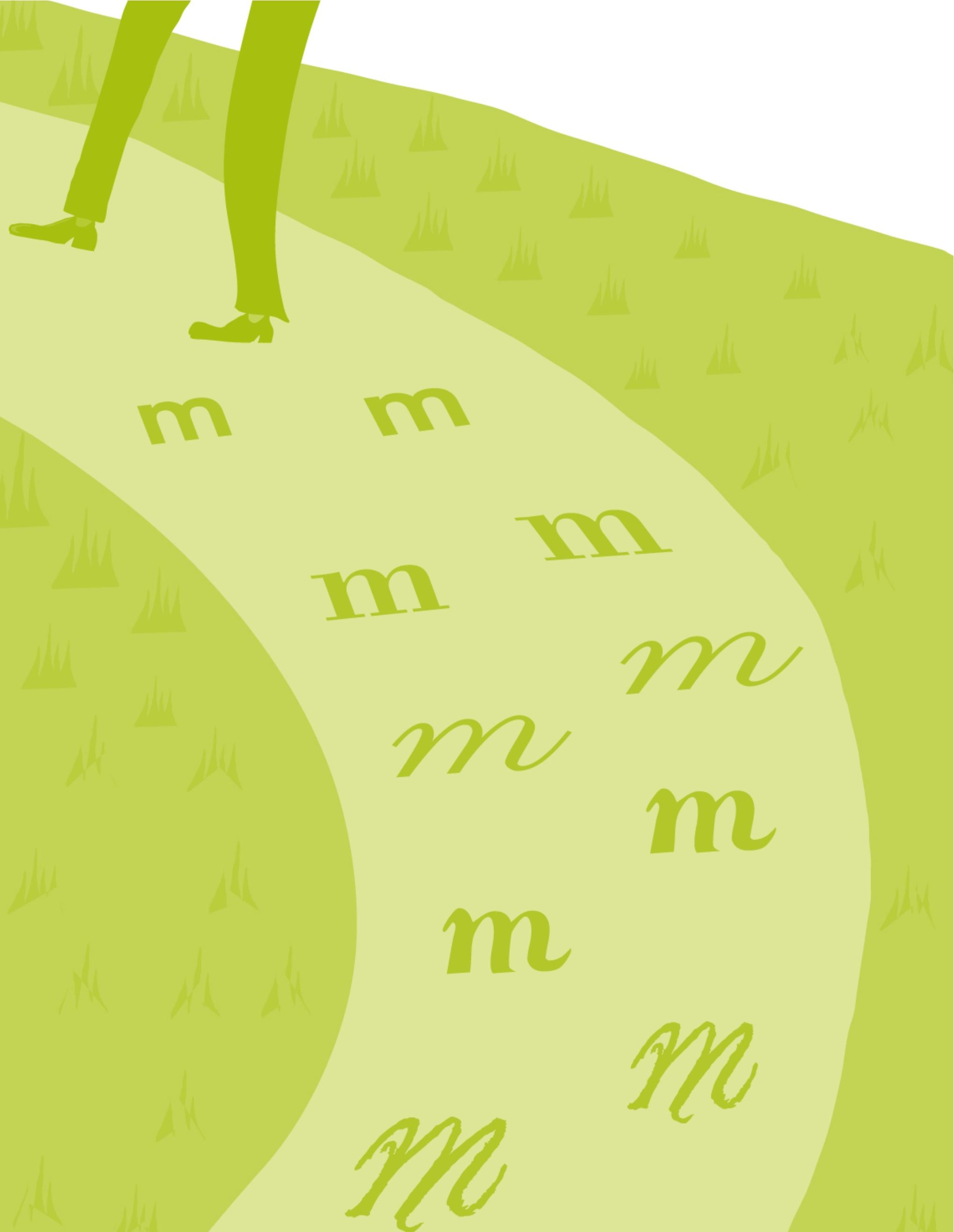




\section{A reputação sob a lógica do tempo real}

Mário Rosa

- Professor dos cursos de MBA da Fundação Instituto de Administração (FIA), ligada à Universidade de São Paulo (USP)

- Autor de três livros que tratam da questão da imagem: $A$ reputação na velocidade do pensamento, A síndrome de Aquiles: como lidar com as crises de imagem e A era do escândalo: lições, relatos e bastidores de quem viveu as grandes crises de imagem

- Consultor de Comunicação Corporativa e Institucional

-mrconsultoria@uol.com.br 


\section{Resumo}

Este artigo analisa a reputação, em sentido amplo, à luz dos recentes adventos tecnológicos, marcados pelo que se chamou de "Revolução Tecnológica", divisor de águas que inaugurou uma nova era histórica e social com reflexos nas esferas ética, moral e comportamental em escala global.

PALAVRAS-CHAVE: REPUTAÇÃO • REPUTAÇÃO CORPORATIVA • REVOLUÇÃO TECNOLÓGICA • ÉTICA

\section{Abstract}

This article analyzes reputation, in its broadest sense, in the light of recent technological advances, marked by what has become to be known as the "Technological Revolution", a milestone that opened a new historical and social era, with reflections on a global scale in the ethical, moral and behavioral spheres.

KEYWORDS: REPUTATION • CORPORATE REPUTATION • TECHNOLOGICAL REVOLUTION • ETHICS

\section{Resumen}

Analiza la reputación, en sentido amplio, a la luz de los recientes descubrimientos tecnológicos, marcados por lo que se llamó "Revolución Tecnológica"; ésta fue un divisor de aguas que inauguró una nueva era histórica y social con reflejos en las esferas ética, moral y comportamental a escala global.

PALABRAS CLAVE: REPUTACIÓN CORPORATIVA • REVOLUCIÓN TECNOLÓGICA • ÉTICA 
Reputações não se sustentam em circunstâncias abstratas. São defendidas, expostas, destacam-se ou fenecem sob o impacto de contextos sociais e históricos específicos. Muda a sociedade e sua lógica de funcionamento, mudam também os desafios e a forma de preservar reputações de líderes e de organizações.

É com base nessa premissa que proponho uma análise sobre até que ponto continuam válidos os pressupostos para pensarmos sobre reputação, especialmente no âmbito das Relações Públicas e, sobretudo, considerando-se o corte histórico fundamental que acabamos de sofrer: refiro-me às transformações impostas e propostas pelo que genericamente se chama de "Revolução Tecnológica", essa transformação de alto impacto e profundo alcance que eclodiu uma década atrás, com reflexos formidáveis sobre o comportamento e o ordenamento de nosso ambiente social.

Em seu livro pioneiro sobre esses novos tempos, o apóstolo da sociedade digital e fundador da Microsoft, Bill Gates, já previa em seu A empresa na velocidade do pensamento, de 1999, que os negócios sofreriam nos dez anos seguintes transformações mais profundas do que haviam experimentado nos 50 anos anteriores. Esse futuro chegou e se chama "hoje".

Se no campo das relações econômicas essa visão se confirmou como uma mudança de paradigma amplamente esmiuçada e investigada em numerosos compêndios sobre os modelos de produção e o salto geral da produtividade, o impacto dessa variável tecnológica sobre a imagem de pessoas físicas e jurídicas ainda carece de maior reflexão.

\section{Nova tecnologia, nova ética}

Para iniciarmos nossa travessia nesse tema, é preciso lembrar o que a História nos ensina: os grandes saltos tecnológicos costumaram ser sucedidos por transformações na ética e na moral. Quando o homem consolidou o conjunto de conhecimentos necessários para dominar as técnicas de agricultura, uma das primeiras conseqüências sociais foi o gradual fim do canibalismo. Com o surgimento da possibilidade de armazenar excedentes, a idéia de devorar adversários de outras tribos foi cedendo espaço para a escravidão dos subjugados nas batalhas. Mesmo que ainda de modo bastante primitivo, inegavelmente constituiu-se num progresso moral notável. Ou seja, a revolução tecnológica denominada agricultura produziu uma transformação no com- 
portamento: o valor ético da vida passou a ser mais respeitado, por força de um novo paradigma tecnológico conquistado pela espécie humana.

Milhares e milhares de anos depois, quando James Watt desenvolve sua máquina a vapor e desencadeia aquilo que viria a ser chamado de "Revolução Industrial", essa nova mudança de paradigma tecnológico provoca outra transformação na moral e nos costumes. Como era necessário pelo novo modelo econômico então proposto que os trabalhadores tivessem renda inclusive para adquirir os produtos que jorravam em escalas torrenciais das linhas de produção, o artefato de James Watt na prática acabou significando uma sentença de morte para a lógica da escravidão. Uma nova revolução tecnológica impunha uma nova revolução na ética e na moral, fazendo com que o valor ético da liberdade passasse a ser mais respeitado.

Os dois exemplos devem ser colocados sob a perspectiva atual: se os saltos tecnológicos do passado trouxeram como conseqüência mudanças na ética e na moral, qual não será o impacto sobre os costumes e a visibilidade das reputações nos dias de hoje de um fenômeno tão poderoso que se auto-intitula "Revolução Tecnológica"? Se as "revoluções tecnológicas" do passado produziram novas lógicas de funcionamento da sociedade e da exposição de imagens públicas, o que se imaginar desses novos tempos que o mundo recém-inaugurou?

Fundamentalmente, é preciso reconhecer que nova tecnologia não significa apenas uma nova teoria. Significa uma nova forma de pensar, sim, mas, sobretudo, exige uma nova forma de agir. Inovação tecnológica significa inovação moral. E essas inovações impactam diretamente na forma de planejarmos e posicionarmos as reputações nesses novos tempos. Vivemos não apenas num novo ambiente social: passamos a viver, de uma década para cá, num novo ambiente moral, com novas regras de comportamento, com novas exigências, onde transgressões que antes podiam passar despercebidas podem agora ser expostas em tempo real, em escala global.

\section{Velhos condicionamentos: a nova vulnerabilidade}

Do ponto de vista da imagem pública, o que nos separa da década passada, dos anos 1990, não são apenas dez anos. É uma unidade histórica inteira: uma era. O que nos separa da década anterior é um abismo histórico. Passamos a viver num mundo funcionando sob novos códigos, sob nova lógica, sob novas premissas. Passamos a enfrentar novos desafios, novos riscos e passamos também a divisar novas oportunidades em tudo que diz respeito à percepção e à exposição de imagens públicas ou institucionais.

A "falha de São Francisco" que acomete organizações e líderes nesses novos tempos pode ser resumida a uma vulnerabilidade fundamental: boa parte daqueles responsáveis pela liderança e a visibilidade de suas carreiras e organizações nos tempos de ho- 
je foram criados num ambiente histórico e tecnológico que não existe mais, aquele que predominava até meados da década passada, até a outra borda do abismo que a sociedade humana deixou para trás. O desafio primordial é que essa geração formada naquele estágio tecnológico é diária e crescentemente instada a defender as suas reputações ou a das organizações que representa num mundo funcionando sob a nova lógica do tempo real.

Eis então onde reside o perigo: ao usar condicionamentos ultrapassados, condicionamentos que poderiam ser válidos para aquele mundo que existia até uma década atrás, mas que talvez não sejam mais suficientes, essa geração hoje no comando desenvolve cenários estratégicos que podem não incorporar os novos fatores de risco diante de reputações e imagens públicas. É como se as reputações atravessassem diariamente uma grande avenida de trânsito intenso, no horário de pico, sem olhar para os lados. Resultado? Danos de reputação, arranhões de imagem, perda de credibilidade pública, de poder simbólico.

Vistos sob essa perspectiva, podemos concluir que os abalos de credibilidade e reputação que se sucedem na crônica do dia-a-dia não são apenas fruto de um descasamento moral. São também resultado de uma defasagem tecnológica, de uma incapacidade infelizmente generalizada de perceber (sobretudo nos núcleos de comando) que certas atitudes que antes poderiam escapar do escrutínio público passaram a estar expostas de uma forma que seus protagonistas, muitas vezes, talvez não consigam perceber.

Esse é o grande campo minado das reputações nos dias de hoje e deve estar no topo de qualquer esforço dos profissionais de comunicação e Relações Públicas: como suprir a defasagem de entendimento dessa geração de transição, hoje no topo das organizações? Muitos dos condicionamentos em termos de visibilidade e de imagem pública que essa geração herdou de seus antecessores ela provavelmente não poderá deixar como legado - por estarem sucateados, simplesmente.
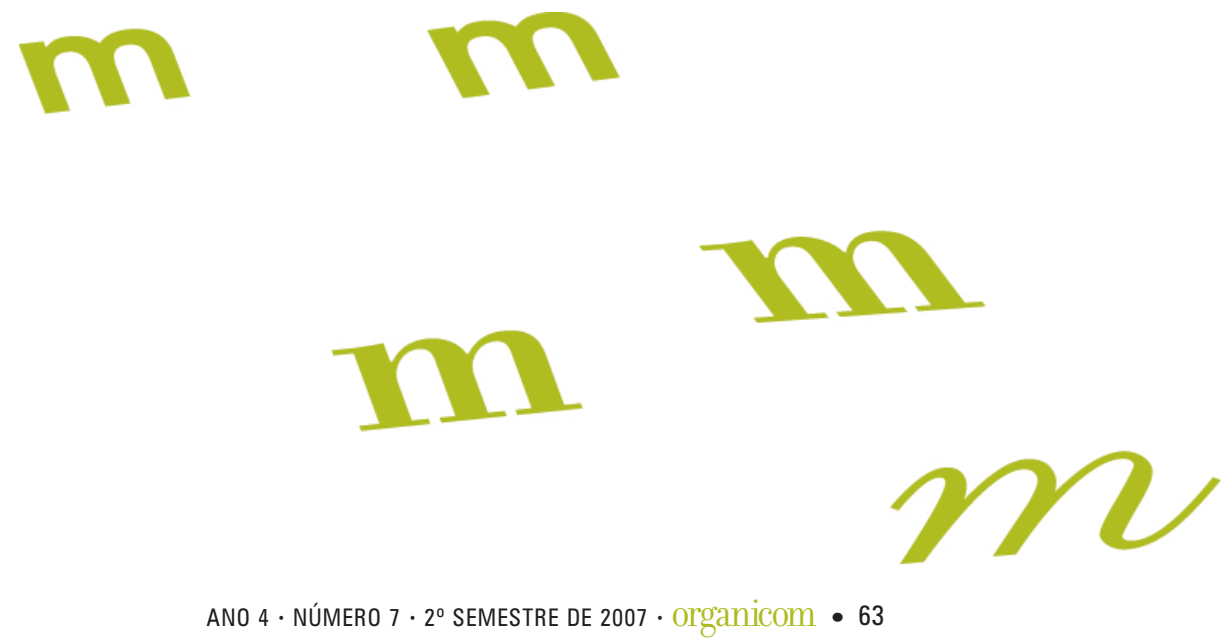


\section{Os novos condicionamentos}

Nesta nova sociedade digital em que passamos a habitar, a palavra convergência assumiu as dimensões de um mantra. Convergência significa a proeza técnica de fazer convergir o mundo e o universo da informação em tempo real para a tela de uma tevê, de um computador ou de um celular. Mas nesses novos tempos muitos têm-se esquecido de que a convergência é uma via de mão dupla. E a contramão da convergência, perigosamente, não vem sendo devidamente considerada por tantos outros.

Convergência significa dizer que "eu vejo o mundo". A contramão da convergência significa entender que "o mundo me vê". Convergência é estar perto do mundo todo. A contramão desse processo é reconhecer que o mundo todo está mais perto de nós. Mais perto especialmente de nossos erros. Nossos erros, portanto, estão mais próximos do mundo inteiro do que costumavam estar até pouco tempo: esse é o grande novo condicionamento a ser incorporado.

Estamos muito mais em público do que estávamos até meados da década de 1990. Estamos em público dentro do elevador (a microcâmera registra nossos gestos e a imagem pode viajar pelo mundo). Celulares com câmeras de fotografia e de filmagem são muito mais do que artefatos: são o olhar do mundo, a preços cada vez mais baratos. Câmeras em vias públicas, micro equipamentos, redes mundiais de comunicação: passamos a viver num novo ecossistema, o ecossistema digital. Não somos mais o Homo Sapiens. Somos o Homo Bytens.

Somos agora todos pessoas públicas. Estamos em público quando mandamos ou recebemos um e-mail, mesmo que o computador esteja instalado no porão. Estamos em público quando falamos ao telefone, quando trocamos uma mensagem no traba1ho. Estamos muito mais em público do que nos acostumamos a pensar que estamos. E toda vez que desconhecemos essa nova realidade, reputações passam a estar na berlinda. Pelo simples motivo de que, se todos estamos mais em público, as reputações estão muito mais expostas - sobretudo a arranhões e polêmicas de todo o tipo.

Mais tecnologia, na prática, significa ser capaz de expor tudo em níveis de detalhes cada vez menores. Isso vale para a Medicina, na qual a tecnologia da tomografia computadorizada permite olhar dentro das profundezas de nossas artérias e antever problemas invisíveis até recentemente. A tecnologia é, antes de tudo, um ambiente social: até nossas artérias estão mais expostas. Expostas ao mundo todo. Não são apenas os líderes e organizações que estão mais expostos. Não são apenas as reputações. Tudo está mais exposto, para o bem ou para o mal. Inclusive nossas entranhas.

Isso traz como conseqüência compreender que a escala do erro mudou. O pequeno erro de uma década atrás pode ser, hoje, a enorme contradição. Apenas porque hoje é possível captá-lo e difundi-lo numa escala sem precedentes. Todos estão mais pró- 
ximos de nós. E quando tudo está mais próximo, tudo está maior. Inclusive as transgressões, que estão mais expostas do que jamais estiveram.

Esse é outro grande condicionamento que está faltando para muitos líderes e instituições: a percepção de que a revolução tecnológica alterou de maneira definitiva os alicerces da noção de público e privado. Um mundo onde todos estão mais expostos significa um mundo onde todos estamos sendo monitorados o tempo todo. Passamos a viver num mundo onde há muito mais vigilância.

Estamos todos expostos em níveis de detalhes cada vez menores. É preciso, então, planejar e prever a possibilidade de danos a reputações, no mínimo, no mesmo grau em que elas já estão expostas. Gerir reputação, nos dias de hoje, significa, em primeiro lugar, compreender o ecossistema digital ao nosso redor e, com base nessa compreensão, agir sobre as variáveis da prevenção. Essa é a resposta prática para romper os grilhões dos velhos condicionamentos, na questão da imagem e da reputação.

É preciso, por fim, entender que os bilhões e bilhões de aparelhos tecnológicos que inundam todos os espaços da vida cotidiana, todos os dias, a todo momento, produziram uma mudança na balança do poder da reputação. No livro 1984, o Big Brother era descrito como um instrumento de concentração de poder nas mãos dos poderosos. Na ficção, a tecnologia permitiria aos mais fortes exercerem ainda mais poder sobre os mais fracos (todos nós, os cidadãos comuns).

No Big Brother de verdade, aquele que vivemos no dia-a-dia após a revolução do mundo on-line, podemos constatar que a realidade mostrou-se muito mais otimista do que a ficção. No Big Brother real, a democratização da tecnologia, por meio de aparelhos cada vez mais baratos, estabeleceu o Big Brother reverso: o controle é feito de cima para baixo, mas, de baixo para cima, os poderosos estão cada vez mais monitorados, cada vez mais vigiados por uma legião de anônimos que todos os dias sai de casa e pode produzir um flagrante devastador para inúmeras e cintilantes reputações. O mundo agora não é só dos mais fortes. É, cada vez mais, dos mais fracos também.

E os mais fortes, mais expostos do que nunca ao olhar alheio, precisarão praticar um olhar permanente de prevenção, indo cada vez mais a detalhes cada vez menores de suas operações. Se a escala do erro mudou como mudou, será preciso inspirar confiança em atitudes cada vez mais microscópicas também.

\section{Gestores de confiança}

Sabemos que uma imagem está baseada na percepção. E o que determina uma percepção positiva ou negativa são os valores associados a uma imagem. Por isso, o esforço de consolidar uma reputação deve ser permanente, porque devemos atuar ar- 
Num mundo em que, como vimos, passou a funcionar num novo ambiente moral, impondo uma nova forma de exposição e não-exposição, a gestão de confiança (ou a gestão de reputação) é um valor que se constitui na única variável preventiva capaz de salvaguardar os interesses das reputações. Esse valor significa entender e praticar um novo alinhamento ético. É preciso estar alinhado à ética em transformação nesse novo território social, em níveis cada vez mais profundos, sob o risco de sermos pilhados de modo crescentemente brutal.

Pois um mundo em que todos estão mais próximos de todos (sobretudo dos erros de todos), um mundo onde há muito mais vigilância, onde uma mínima contradição pode adquirir exposição literalmente global, um mundo onde somos todos bombardeados por uma miríade de informações o tempo todo, onde quer que estejamos, exige que decisões cruciais sejam tomadas em tempo cada vez mais escasso. Em resumo: um mundo funcionando "na velocidade do pensamento" expõe todas as reputações a um sentimento geral de desconfiança, pois todos estão mais vulneráveis diante de cada vez mais escolhas, feitas de forma cada vez mais rápida. E potencialmente perigosas. Há um ambiente de muito maior insegurança. De desconfiança.

Por isso, a reputação que sempre foi importante passou a ser fundamental. Ter uma boa reputação, obviamente, não é sinônimo de escolha. Não significa que, por si só, garantirá que nossos produtos ou nossos serviços serão premiados pela escolha dos outros. Mas, num mundo em que os desgastes de imagem são instantâneos e de escala mundial, se reputação não é sinônimo de escolha, a perda dela pode representar um passaporte para o descarte.

Por essa razão, os profissionais de Relações Públicas e todos aqueles que se dedicam a refletir e planejar as imagens de suas organizações assumem uma missão que vai muito além de propagar uma percepção. Cabe a eles, no dia-a-dia do ambiente social, atuar como gestores desse ativo tão sutil que é a confiança tão necessária para que os outros continuem honrando nossos produtos e serviços com esse milagre tão inexplicável por trás de cada escolha.

\section{A ética como fator competitivo}

Nesse novo contexto social, o respeito aos novos parâmetros éticos que se impõem deixa de ser um recurso retórico, um discurso politicamente correto, para se transformar numa necessidade competitiva. Pode-se encarar essa questão com base em uma opção pessoal: adotar melhores práticas pelo simples motivo de considerar que um mundo funcionando sob determinados valores cria um ambiente melhor para a coletividade. Pode-se examinar essa questão pela ótica estrita da lei da oferta e da procura: se há mais demanda social por ética, é preciso atendê-la, sob o risco de que o concorrente o faça. Seja como for, o fato objetivo é que pesquisas feitas no mundo in- 
teiro mostram que uma boa reputação oferece um leque amplo de vantagens competitivas. É o que chamo de os cinco "cês" da credibilidade, os cinco "cês" da boa reputação.

A primeira vantagem competitiva da ética - o primeiro "cê" de uma boa reputação é que uma reputação positiva compra melhor! Se uma empresa é respeitada e tem uma imagem positiva, naturalmente ela tem maiores e melhores condições de negociar e de comprar mais barato que uma concorrente com reputação duvidosa. Quem tem boa reputação pode pagar menos ou conquistar condições mais favoráveis basicamente porque o outro confia mais e quer manter aquele bom cliente. Essa vantagem competitiva vale para pessoas físicas e jurídicas, sem distinção.

Chegamos ao segundo "cê": uma boa reputação cobra melhor! Se uma empresa ou um profissional tem uma reputação mais positiva, essa diferenciação lhe permite que possa cobrar mais caro. Afinal, haverá sempre gente disposta a pagar mais por um serviço que desperta maior confiança. Isso vale para uma multinacional do setor alimentício ou farmacêutico, cuja marca mais respeitada permite vender um produto mais caro. Mas para um médico ou um mecânico é mais ou menos a mesma coisa.

O terceiro "cê" da reputação é que uma boa reputação contrata melhor! Uma empresa mais admirada consegue atrair o interesse e despertar a ambição dos melhores profissionais. Já uma empresa com reputação ruim os melhores cérebros com certeza tentarão evitar. O resultado desse efeito magnético que a reputação exerce sobre os melhores quadros é que, contratando os melhores, a empresa passa a ter uma vantagem a mais sobre a concorrente. Empresa é, antes de tudo, gente.

Uma empresa com boa reputação compete melhor! Esse é o quarto "cê”, quase uma resultante dos outros já elencados. Compete melhor porque uma boa reputação afasta o profissional ou a organização de desgastes de imagem, de crises, escândalos, problemas jurídicos. E isso tudo custa dinheiro. Muito dinheiro. Uma boa reputação garante clientes e consumidores mais fiéis. Oferece mais solidez para uma carreira a médio e longo prazos. Isso sem contar que todo mundo quer estar próximo de quem tem uma boa imagem. Com isso, chegam até você novas chances de fazer negócios, de ganhar dinheiro e prosperar. De crescer.

Por fim, o quinto "cê" de uma boa reputação: reputações positivas custam melhor! Fundamentalmente, custam melhor porque custam menos. Uma empresa ou uma pessoa que tem ficha limpa conseguem empréstimo num banco a juros mais baixos. Isso sem contar que, se você compra mais barato (porque tem uma boa reputação e as pessoas confiam em você) e vende mais caro (porque há quem queira pagar um pouco mais pela garantia que seu nome ou sua marca oferecem), isso significa que sua margem de lucro é maior. 
O que todos esses "cês" da credibilidade comprovam é que boa reputação é algo que está muito além da mera vaidade. Preservar a reputação e esforçar-se duramente para que ela se mantenha acima de controvérsias e desgastes não é um capricho ou um modismo desses tempos do politicamente correto. Boa reputação é uma vantagem competitiva crucial. E auditável, inclusive.

Um projeto conduzido pela Universidade de Kansas, nos Estados Unidos, pesquisou o valor de mercado das 500 maiores empresas americanas listadas pela revista Fortune, entre 1983 e 1997. Os pesquisadores cruzaram o valor das empresas com a qualidade de sua reputação corporativa. A conclusão foi a seguinte: cada ponto a mais na escala da reputação significava 500 milhões de dólares no valor da empresa.

Num mundo onde muitas vezes assistimos ao triunfo dos desmandos, o recado dessa pesquisa não poderia ser mais claro. Ao contrário do que o pessimismo moral de alguns pode imaginar, a ética não é tema abstrato ou do bom mocismo: é, principalmente, um bom negócio. 